\title{
Future Lyme disease risk in the south-eastern United States based on projected land cover
}

\author{
Logan K. Stevens, ${ }^{1}$ Korine N. Kolivras, ${ }^{1}$ Yili Hong, ${ }^{2}$ Valerie A. Thomas, ${ }^{3}$ James B. Campbell, ${ }^{1}$ \\ Stephen P. Prisley ${ }^{4}$ \\ ${ }^{1}$ Department of Geography, Virginia Tech, Blacksburg, Virginia; ${ }^{2}$ Department of Statistics, Virginia Tech, \\ Blacksburg, Virginia; ${ }^{3}$ Department of Forest Resources and Environmental Conservation, Virginia Tech, \\ Blacksburg, Virginia; ${ }^{4}$ National Council for Air and Stream Improvement, North Carolina, USA
}

\begin{abstract}
Lyme disease is the most significant vector-borne disease in the United States, and its southward advance over several decades has been quantified. Previous research has examined the potential role of climate change on the disease's expansion, but no studies have considered the role of future land cover upon its distribution. This research examines Lyme disease risk in the south-eastern U.S. based on projected land cover developed under four Intergovernmental Panel on Climate Change Scenarios: A1B, A2, B1, and B2. Land cover types and edge indices significantly associated with Lyme disease in Virginia were incorporated into a spatial Poisson regression model to quantify potential land cover suitability for Lyme disease in the south-eastern U.S. under each scenario. Our results indicate an intensification of potential land cover suitability for Lyme disease under the A scenarios and a
\end{abstract}

Correspondence: Logan K. Stevens, Department of Geography, Virginia Tech, Blacksburg, Virginia, 24061, USA.

Tel.: +1.859.663.8931.

E-mail: LKS12@vt.edu

Key words: Lyme disease; Medical geography; GIS; Spatial Poisson regression; Land cover; USA.

Contributions: LKS, data collection, analysis, manuscript writing; $\mathrm{KNK}$, analysis and interpretation of results, manuscript writing; VAT, $\mathrm{JBC}$, analysis decision making, manuscript editing; YH, statistical analysis and interpretation; SPP, development of conceptual idea.

Conflict of interest: the authors declare no potential conflict of interest.

Funding: none.

Received for publication: 6 November 2018 .

Revision received: 2 March 2019.

Accepted for publication: 11 March 2019.

(C) Copyright L.K. Stevens et al., 2019

Licensee PAGEPress, Italy

Geospatial Health 2019; 14:751

doi:10.4081/gh.2019.751

This article is distributed under the terms of the Creative Commons Attribution Noncommercial License (CC BY-NC 4.0) which permits any noncommercial use, distribution, and reproduction in any medium, provided the original author(s) and source are credited. decrease of potential land cover suitability under the B scenarios. The decrease under the $\mathrm{B}$ scenarios is a critical result, indicating that Lyme disease risk can be decreased by making different land cover choices. Additionally, health officials can focus efforts in projected high incidence areas.

\section{Introduction}

Lyme disease, the most common vector-borne disease in the United States, is caused by the bacterium Borrelia burgdorferi, which is transmitted to humans through the bite of a blacklegged tick (Ixodes scapularis) in the eastern U.S. (Lantos et al., 2015). The disease can cause fever, fatigue, muscular aches, and a distinguishing skin rash, erythema migrans (Lantos et al., 2015). In addition, if the disease is left untreated, debilitating side effects can affect joints, the heart, and the nervous system (Lantos et al., 2015). The majority (90\%) of Lyme disease cases in the U.S. are contracted along the East Coast from New England to southern Virginia (Lantos et al., 2015). First identified in the 1970's in New England, Lyme disease continues to experience a range expansion as demonstrated in a study completed in Virginia; Lyme disease expanded southward during the study period of 1998-2011 (Li et al., 2014). Most noteworthy is that $74 \%$ of Virginia's cases were contracted in the last five years of the study period (Li et al., 2014). Although the disease's approximate range currently ends near the North Carolina border, it is likely to continue its southward expansion as five counties in North Carolina have met clinical surveillance criteria for Lyme disease since 2009 (Lantos et al., 2015).

Considerable research has examined Lyme disease's emergence and distribution. A number of themes have emerged, covering a wide variety of approaches, explanatory variables, and locations in the U.S. and elsewhere around the world, including Canada, and Europe (Lindgren and Jaenson, 2006; Simon et al., 2014; Mysterud et al., 2016). More specifically, much research has been devoted to understanding effects of land cover change, estimating potential shifts in Lyme disease distribution as a result of climate change, and tracking Lyme disease spatially over the landscape. There is little research on Lyme disease along the southern extent of the disease's range, and no research has quantified its potential distributions based on projected land cover. An understanding of the areas in the south-eastern U.S. that may be characterized by landscape factors known to be correlated with this disease will aid public health officials in those areas as Lyme disease continues to emerge.

Understanding the distribution of the tick and reservoirs, as 
well as their relationship with land cover, is necessary in considerations of future Lyme disease distributions. Ticks feed on a variety of animals, including birds, reptiles, and amphibians, but the white-footed mouse is the most competent reservoir for the $B$. burgdorferi bacterium in the eastern U.S. An infected white-footed mouse can infect up to $75-90 \%$ of larval ticks, and these immature blacklegged ticks cause the majority of human infections because of their very small size, by which nymphal ticks latch onto human hosts unnoticed (Simon et al., 2014). Throughout the south-eastern U.S., the blacklegged tick and white-footed mouse habitats overlap substantially, indicating that the Lyme disease transmission cycle can be supported as the disease continues to expand southward. Adult ticks will typically mate on large animals, such as the whitetailed deer, with the potential of being transported relatively long distances, introducing infected ticks to new areas.

Land cover characteristics and configuration can affect the spread and incidence of Lyme disease, as those variables impact the density of, and interactions between, hosts, the vector, and reservoirs. An abundance of edge environments, the boundary between different land cover types, can amplify Lyme disease risk because white-tailed deer, which are the primary host for adult ticks, and white-footed mice, which are the primary host for nymphal ticks, flourish in edge environments (Simon et al., 2014; Seukep et al., 2015). Patchy, fragmented landscapes, which have longer edges than contiguous landscapes, support Lyme disease transmission. White-footed mice generally have a higher abundance in smaller forest fragments due to the lack of competition and predators inside forest fragments (Brownstein et al., 2005; Khatchikian et al., 2012). Since small patches of forest result in lower biodiversity and fewer predators to the white-footed mouse, a tick feeding inside a small forest fragment is more likely to feed on a white-footed mouse than a different, likely less competent, reservoir, such as the eastern chipmunk or the American robin. Horobik et al. (2007) found that a higher level of edge environments resulted in a higher risk of Lyme disease in forest patches' interiors in a study of edge environments in south-eastern New York. Results of a different study showed that nymphal tick density was three times higher inside the smallest selected forest patches than in forest patches greater than 1.2 hectares (Brownstein et al., 2005). When specifically examining human Lyme disease, anthropogenic changes to the environment have been identified as a contributor to the increase of human Lyme disease (Khatchikian et al., 2012); as suburbanization, reforestation, or other landscape modifications occur, different types of edges between land cover types are created. Forest-herbaceous and herbaceous-developed edge environments were found to be positively and negatively, respectively, associated with Lyme disease in Virginia (Seukep et al., 2015). Moreover, the forest-herbaceous edge, as measured using the edge-contrast index, was found to be the most influential characteristic of Lyme disease incidence in Jackson et al.'s (2006a, 2006b) study of Lyme disease emergence in Maryland, with every $10 \%$ increase in the value of the edge-contrast index corresponding to a $34 \%$ increase in Lyme disease incidence rate. Overall, fragmented forests provide more edge environments in which whitetailed deer thrive and in suburban areas where hunting is essentially non-existent, white-tailed deer populations tend to be high (Brownstein et al., 2005). Therefore, fragmented landscapes support both white-tailed deer and white-footed mouse populations, thereby contributing to human Lyme disease transmission.

Previous studies have quantified the potential future range of Lyme disease under projected climate conditions, but no study has examined potential distributions under projected land cover, despite a strong association between land cover and Lyme disease outlined previously (Ogden et al., 2006; Simon et al., 2014; Tran and Waller, 2013). In this study, we quantify the potential continued emergence of Lyme disease in the south-eastern U.S. under four different land cover situations produced using the Intergovernmental Panel on Climate Change (IPCC) Special Report on Emissions Scenarios (SRES). Specifically, we seek to answer the following research questions: i) Based on current relationships between Lyme disease and land cover, how will future land cover configurations affect the suitability for Lyme disease throughout the south-eastern U.S.? ii) Where should public health agencies in the south-eastern U.S. apply Lyme disease control and education efforts in the future based on projected land cover patterns? Results of this research will contribute to understanding the potential direction and magnitude of Lyme disease's continued emergence, based on projected land cover. Risk maps will improve public health officials' understanding of Lyme disease's potential spread within the region and the processes that can be implemented to prevent and control outbreaks. Results of the research can be used to educate the general public living in this region about potential future Lyme disease dissemination.

\section{Materials and Methods}

\section{Data}

Projected land cover data based on a model described by Sohl et al. (2012) was acquired from the U.S. Geological Survey (USGS) (Sohl et al., 2012; USGS, 2012). The land cover datasets ( $250 \mathrm{~m}$ resolution) provide spatial and temporal scenarios of land use and land cover from decadal increments 2020 to 2100 . The seventeen land cover classifications were reclassified using ArcGIS 10.5 into four land cover types: water, developed, forested, and herbaceous cover to match the broad categories used by Seukep et al. (2015), as we apply their results to this study (ESRI, 2017). Land cover percentages for each census tract, which is our unit of analysis, were calculated in ArcGIS 10.5 using the Zonal Statistics as Table tool (ESRI, 2017).

In addition to the land cover variables found to be statistically significantly associated with Lyme disease in Virginia, Seukep et al. (2015) found indices that measure the edge between forest-herbaceous land and herbaceous-developed land to be significant. Reclassified land cover layers for each decadal period under each of the four scenarios were converted to GeoTIFF, and imported into the fragmentation analysis software, FRAGSTATS 4.2, to analyze fragmented edges (McGarigal et al., 2012). The significant edge variables from Seukep et al. (2015) were the forest-herbaceous edge and the herbaceous-developed edge measured using two contrast metrics: Contrast-Weighted Edge Density and Total-Edge Contrast Index. The projected land cover scenarios were developed based on historical land cover conditions combined with the IPCCSRES scenarios A1B, A2, B1, and B2 (USGS, 2012) which represent diverse future possibilities regarding economic, technological, and environmental conditions (IPCC, 2018a). The A1B scenario is characterized by a balance across all energy foci, with strong economic growth, high levels of technological innovation, international mobility of ideas, and high rates of land use/land cover change (Sleeter et al., 2012). Environmental concerns are secondary to economic growth, urban growth is strong, and high pressure on forest 
resources results in an increase of fragmented landscapes (Sleeter $e t$ al., 2012). The A2 scenario describes a continuously increasing population over time, which results in the highest rates of conversion of lands for developed uses of all scenarios (Sleeter et al. 2012); economic and technological growth are primarily regionally-based and increase slower than under the A1B scenario (IPCC, 2018c). The A2 scenario also includes strong governmental support to maintain overproduction with little attention to conservation (Sleeter et al., 2012). Logging and forest cutting intensifies with large areas of cropland becoming more common (Sleeter et al., 2012). The B1 scenario includes rapid change in economic structures toward a service economy with the introduction of resourceefficient technologies (IPCC, 2018c). This scenario also emphasizes global solutions to sustainability but without additional climate initiatives, and is characterized by technological advancement resulting in higher crop yields; however, productivity is balanced against environmental concerns which restrict intensive farming practices (Sleeter et al., 2012). Finally, the B2 scenario depicts a world where the emphasis is focused on local solutions to sustainability and low population growth, along with intermediate levels of economic development with less rapid but more diverse technological change (IPCC, 2018c). The B2 scenario is concerned with environmental protection and social equality on local levels (IPCC, 2018c). Forested areas remain stable due to the overall demand for biofuels (Sleeter et al., 2012).

\section{Study area}

The southeastern U.S. was chosen for this study because there is little to no research to estimate the future spatial distribution of Lyme disease if it continues to expand southward. The current range of human Lyme disease ends roughly near the border of North Carolina and Virginia, and the disease is likely to continue its southward expansion given that five counties in North Carolina have met clinical surveillance criteria for Lyme disease since 2009, and the white-footed mouse, other competent reservoirs, and the blacklegged tick are present in the Southeast (Lantos et al., 2015; CDC, 2017b). Seukep et al. (2015) examined environmental and demographic variables that are correlated with Lyme disease in Virginia; this research uses Level III Ecoregions, as defined by the U.S. Environmental Protection Agency, that are present in Virginia and expands them to their full extent in the Southeast (Figure 1). Ecoregions represent fairly uniform ecosystems in which it would be important to assess Lyme disease risk since its distribution is reliant on specific environmental characteristics and conditions to support the various species involved in the transmission cycle. Where Lyme disease currently exists inside these ecoregions, we argue that future suitable habitats will most likely facilitate Lyme disease expanding into new areas in the south-eastern U.S.

\section{Methods}

A spatial Poisson regression model was developed using the five variables (Table 1) described previously by Seukep et al. (2015) to generate predicted annual incidence rates for each census tract $(n=9872)$ for each scenario for each decadal time period through 2100 (e.g., year 2020, year 2030, etc.).

Here we describe how the model is built based on historical data. Following Seukep et al. (2015), we used the five-year counts for census tract $i$ in the historical data, which is denoted by $y_{i}$. Let $n=1879$ represent the number of census tracts in the study area in the historical data. The variable $m_{i}$ represents the 2010 population for census tract $i$, on the scale of 10,000 people. The variable $x_{i j}$ is the $j^{\text {th }}$ explanatory variable for census tract $i$ where $i=1,2, \ldots, n$ and $j=1,2, \ldots p$ and $p=5$ for the five environmental explanatory variables. In the spatial Poisson regression analysis, the response variable, $y_{i}$, is modeled by a Poisson distribution. That is, $y_{i} \sim \operatorname{Poisson}\left(m_{i} \lambda_{i}\right)$ where $\lambda_{i}$ is interpreted as the five-year incidence rate. In particular, $\lambda_{i}$ is modeled by a log-linear model:

$$
\log \left(\lambda_{i}\right)=\beta_{0}+\beta_{1} x_{i 1}+\cdots+\beta_{p} x_{i p}
$$

Eq. 1

Based on the estimated statistical model in Eq. 1 and the pro-

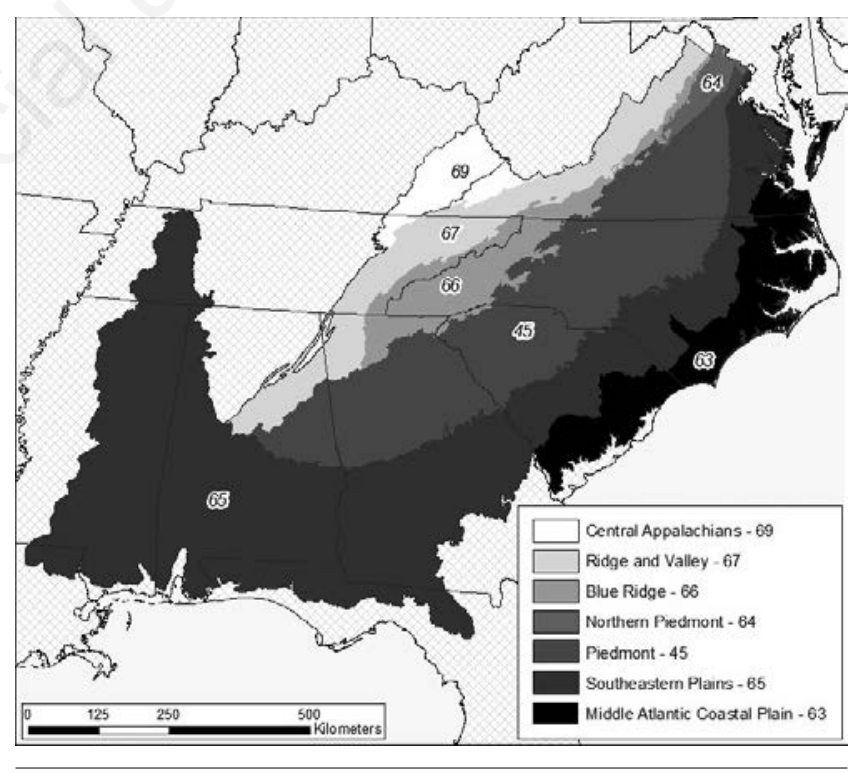

Figure 1. Study area defined by Environmental Protection Agency Level III ecoregions that are present in Virginia.

Table 1. Estimated regression coefficients and significance for environmental variables.

\begin{tabular}{lcccc} 
Variables & Estimate & Standard Error & Zr $(>\mid$ zal $)$ \\
(Intercept) & 0.16109 & 0.17148 & 0.939 & 0.3475 \\
CWED H-D & 0.00021 & 0.00103 & 0.202 & 0.8397 \\
\hline TECI H-D & -0.01706 & 0.00277 & -6.157 & $7.40 \mathrm{e}-15^{* * *}$ \\
TECI F-H & 0.00650 & 0.00202 & 3.211 & $0.0013^{* *}$ \\
\hline \% Developed & 0.01293 & 0.00164 & 7.880 & $3.28 \mathrm{e}-15^{* * *}$ \\
\% Herbaceous & 0.04039 & 0.00124 & 32.512 & $<2.00 \mathrm{e}-16^{* * *}$ \\
\hline
\end{tabular}

CWED H-D, contrast weighted edge density herbaceous-developed; TECI H-D, total edge contrast index herbaceous-developed; TECI F-H, total edge contrast index forested-herbaceous. Statistical significance: $* * * 0$, $* * 0.001, * 0.01$. 
jected explanatory variables at a future year (e.g., year 2020), $x=$ $\left(x_{1}, \ldots, x_{5}\right)$, the predicted annual incidence rate per 10,000 people is obtained as:

$$
\lambda=\frac{\exp \left(\widehat{\beta}_{0}+\widehat{\beta}_{1} x_{1}+\cdots+\widehat{\beta}_{p} x_{p}\right)}{5}
$$

Here the right-hand side of Eq. 2 is divided by five because the model in Eq. 1 is for the five-year rate and we adjusted the fiveyear rate to obtain the annual rate.

We used the prediction in Eq. 2 to determine the projected incidence rate of Lyme disease in each census tract, at each decadal time period, and under each of the four IPCC SRES scenarios across the south-eastern U.S. per 10,000 people. The model gave projected incidence rates, and those rates were classified into categories based on land cover suitability for Lyme disease transmission: 0 (None), 0-0.5 (Low), 0.51-1.0, 1.01-2.0 (Medium), 2.014.0, and 4.01-10.0 (High) cases per 10,000 people.

\section{Results}

The greatest potential Lyme disease suitability occurs in the South-eastern Plains and Middle Atlantic Coastal Plain ecoregions outside urbanized areas (Figure 1). Figure 2 shows the temporal pattern of the highest category of potential land cover suitability under each scenario. The A2 scenario (Figure 3) shows an exponential increase in Lyme disease land cover suitability with an average increase of approximately $16,000 \mathrm{~km}^{2}$ per decade (Table 2 ), with highest potential suitability in the South-eastern Plains, northern Piedmont, as well as the Ridge and Valley ecoregions. The area of the highest category of potential land cover suitability under the A1B scenario (Figure 4) increases nearly linearly, on average, almost 3,500 $\mathrm{km}^{2}$ per decade (Table 2). Highest land cover suitability includes the South-eastern Plains and the northern Piedmont for the A1B scenario.

Conversely, the $\mathrm{B} 1$ and $\mathrm{B} 2$ scenarios showed an average decrease in potential land cover suitability by 2100 . The area of the highest land cover suitability category under the B1 scenario (Figure 5) decreases nearly $600 \mathrm{~km}^{2}$ on average per decade, and places with the highest land cover suitability include the Southeastern Plains and northern portion of the Ridge and Valley. With an average decrease of approximately $2,000 \mathrm{~km}^{2}$ per decade, the B2 scenario (Figure 6) has the greatest decrease of potential land cover suitability for Lyme disease of the four scenarios.

\section{Discussion}

The results of this research provide an indication of where the Lyme disease transmission cycle may be supported in the coming decades as the extent of the disease's distribution continues to expand southward, following the trend of the past several decades. If future land cover change follows the path of the A2 or A1B scenarios, enhanced Lyme disease may occur if the disease continues to spread southward into the south-eastern U.S., while if the B1 or B2 scenarios are followed, we can expect a decrease in areas where the transmission cycle will be supported.

Under the A2 scenario (Figure 3), land cover suitability for Lyme disease is expected to experience the most rapid increase through 2100 of the four scenarios examined here. This scenario is characterized by rapid population growth, resulting in high rates of land conversion for developed uses because of an absence of policies to restrict urban sprawl and a reduced emphasis on environmental conservation that results in intensified forest loss (Sleeter $e t$ al., 2012). Combined, the expected land use changes will result in greater levels of fragmentation and the exponential increase of land cover suitable for Lyme disease through 2100. Under the A1B scenario (Figure 4), land cover suitability for Lyme disease is also expected to increase. This scenario considers environmental regulation a secondary concern to economic growth, and urbanization, population, and fragmented landscapes increase, resulting in increased edge environments that support the Lyme disease transmission cycle (Sleeter et al., 2012).

Under the B1 scenario, a subtle decrease is expected in areas with the highest land cover suitability for Lyme disease (Figure 5). This scenario has similar population and economic growth as A1B, but it, however, considers a high level of environmental and social awareness, along with a global view of sustainability (Sleeter et $a l ., 2012$ ). Urban areas would expand slowly due to preferences towards compact development, and significant efforts are made to increase protected forested land (Sleeter et al., 2012). These factors together would result in lower levels of fragmentation and

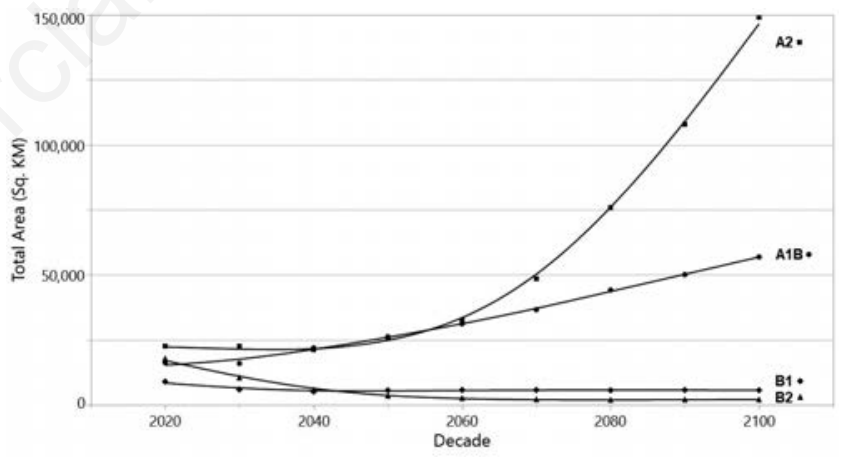

Figure 2. Total area $\left(\mathrm{km}^{2}\right)$ of the highest land cover suitability for each decade through 2100 under four Intergovernmental Panel on Climate Change-Special Report on Emissions Scenarios.

Table 2. Total area for highest land cover suitability category for each scenario $\left(\mathbf{k m}^{2}\right)$.

\begin{tabular}{lcccc} 
Year & A1B & A2 & B1 & B2 \\
2020 & 16,254 & 22,610 & 8,963 & 17,844 \\
2030 & 15,949 & 22,570 & 5,926 & 10,507 \\
\hline 2040 & 21,902 & 21,181 & 5,130 & 5,752 \\
2050 & 26,218 & 25,544 & 5,584 & 3,546 \\
\hline 2060 & 31,192 & 32,536 & 5,730 & 2,590 \\
2070 & 36,616 & 48,475 & 5,726 & 2,140 \\
\hline 2080 & 44,185 & 75,878 & 5,609 & 1,921 \\
2090 & 50,114 & 107,956 & 5,725 & 2,052 \\
\hline 2100 & 56,917 & 149,064 & 5,630 & 2,052 \\
Change 2020-2100 & $250.12 \%$ & $559.29 \%$ & $-37.19 \%$ & $-88.50 \%$ \\
\hline
\end{tabular}


edge environments than under A1B or A2. Finally, under the B2 scenario (Figure 6), the area with the highest levels of land cover suitability for Lyme disease would experience the greatest decline of the four scenarios. Due to low population growth and sustainable practices characterized by this scenario, urban areas might grow more slowly promoting an increase in total forested area by 2100 , resulting in the lowest levels of fragmentation and edge environments of the four scenarios (Sleeter et al., 2012). Overall, these results support future land cover changes leading to the need for decisions to be made in the study area as Lyme disease
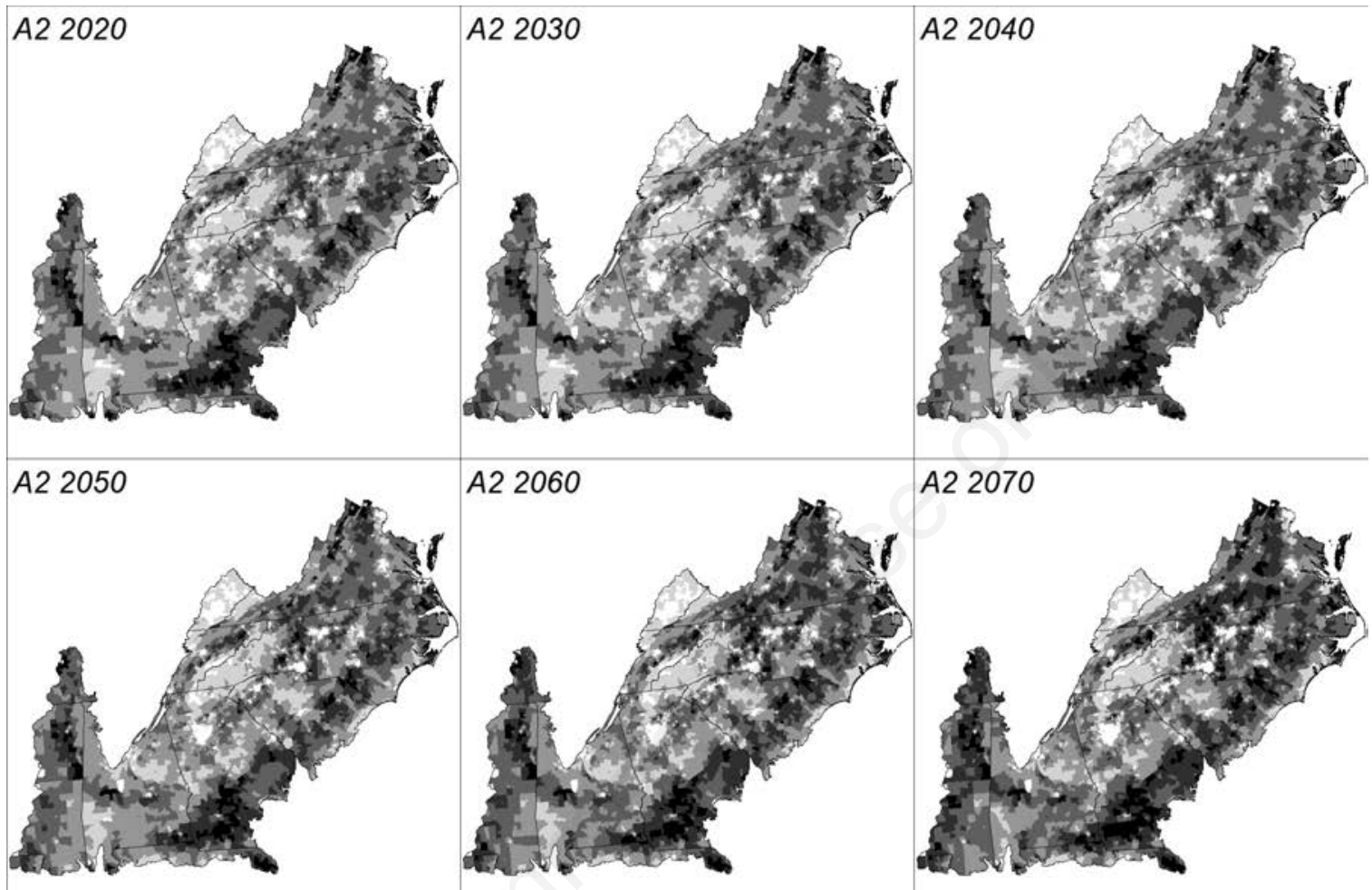

A2 2070
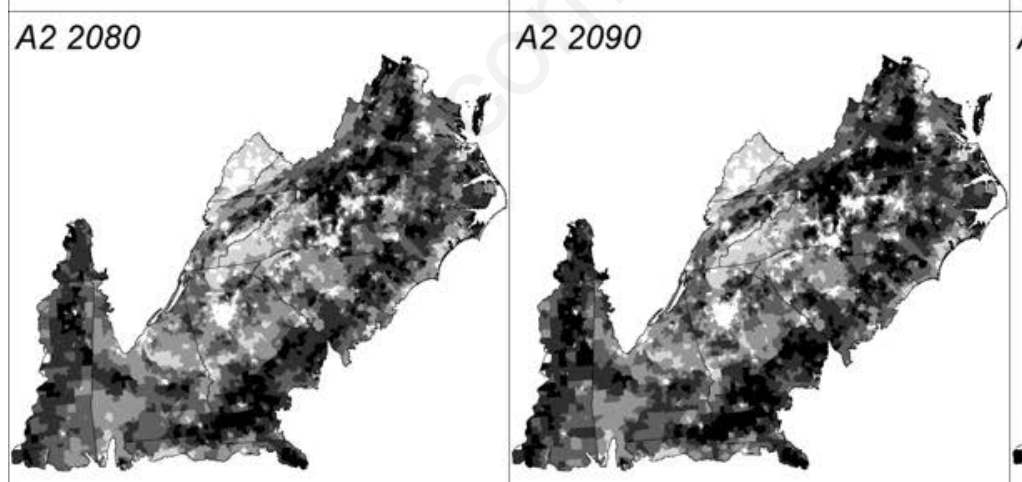

\section{A2 2100}

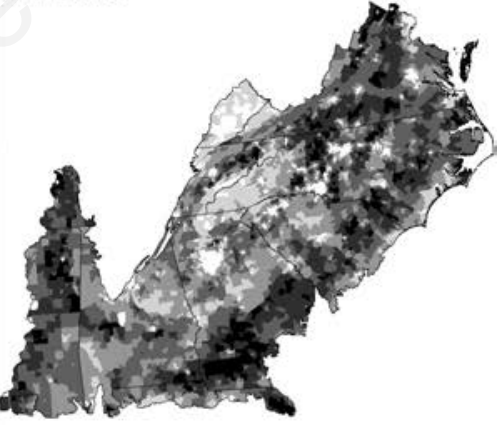

\section{Potential Land Cover Suitability}

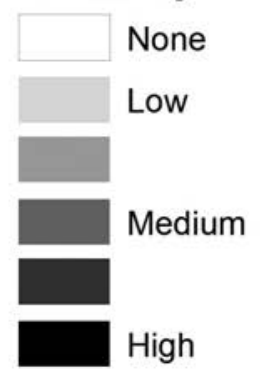


continues to expand southward. For example, careful landscape design, following the B1 or B2 scenarios, could help prevent the establishment of the Lyme disease transmission cycle by inhibiting host and vector interactions. This finding supports recommendations by Jackson et al. (2006a, 2006b), who researched the role of land cover patterns in endemic areas, specifically in Maryland.
These authors suggest that designing landscapes discouraging efficient Lyme disease transmission, such as a countryside with fewer forest-herbaceous edges, could prevent the further emergence of the disease.

Several limitations in this study need to be considered. The census tracts used as the basic unit of analysis were from the 2010

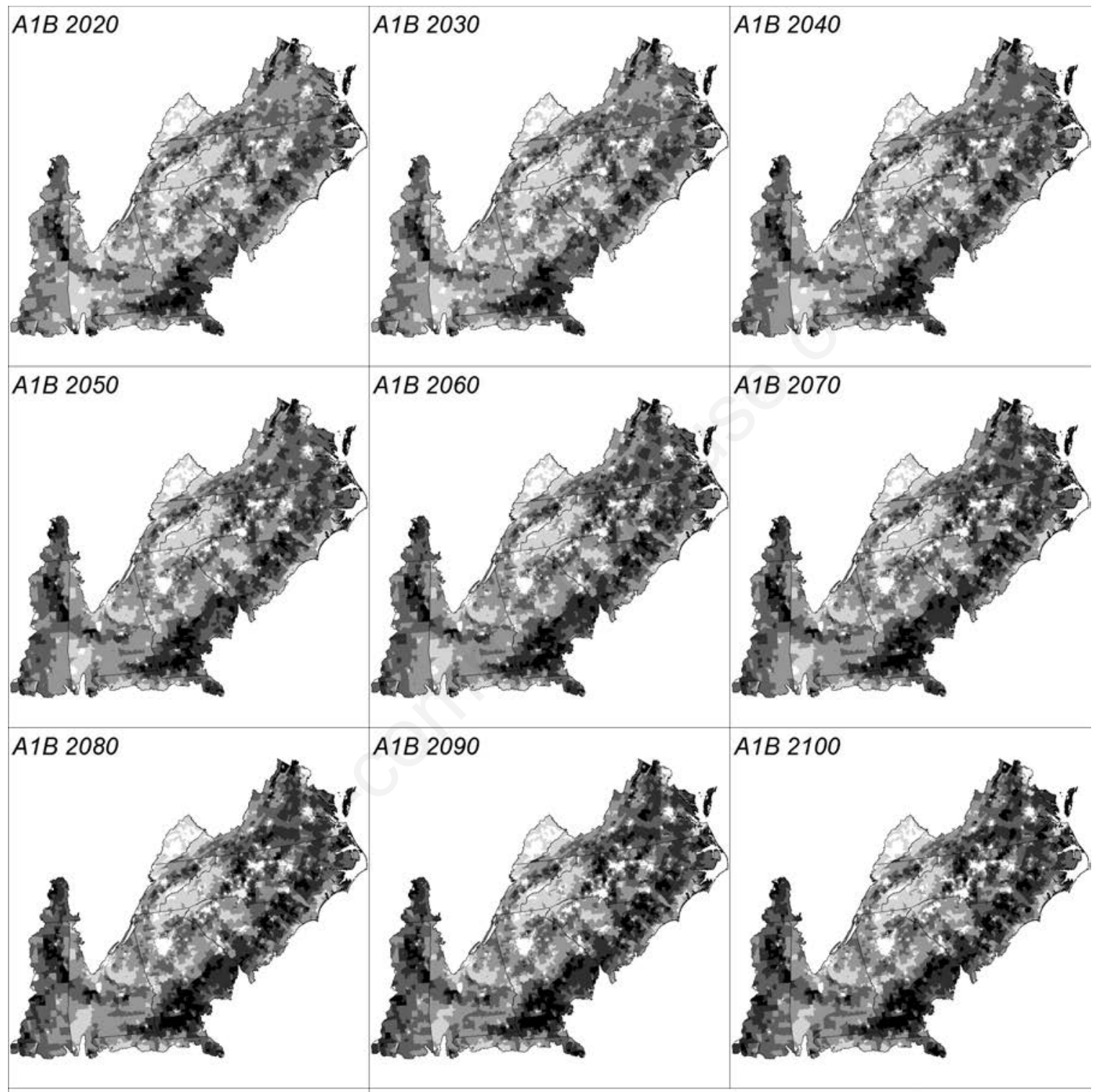

Potential Land Cover Suitability

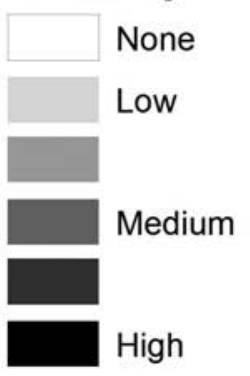


census, and the research does not include changes in the number of census tracts or shape changes in the future, which occur following each decennial census. As we are unable to predict future census tract boundaries, we were unable to address this limitation. The spatial resolution of the land cover scenario raster images was relatively coarse, at 250-meter resolution; however, this dataset is the only available projected land cover data, and projecting land cover at a resolution finer than $250 \mathrm{~m}$ would increase error. Given the broad scale of our analysis, stretching across the south-eastern U. $\mathrm{S}$., we found the relatively course resolution to be acceptable, in the absence of a better option. Finally, the census tract polygons were converted to raster format at the same spatial resolution as the

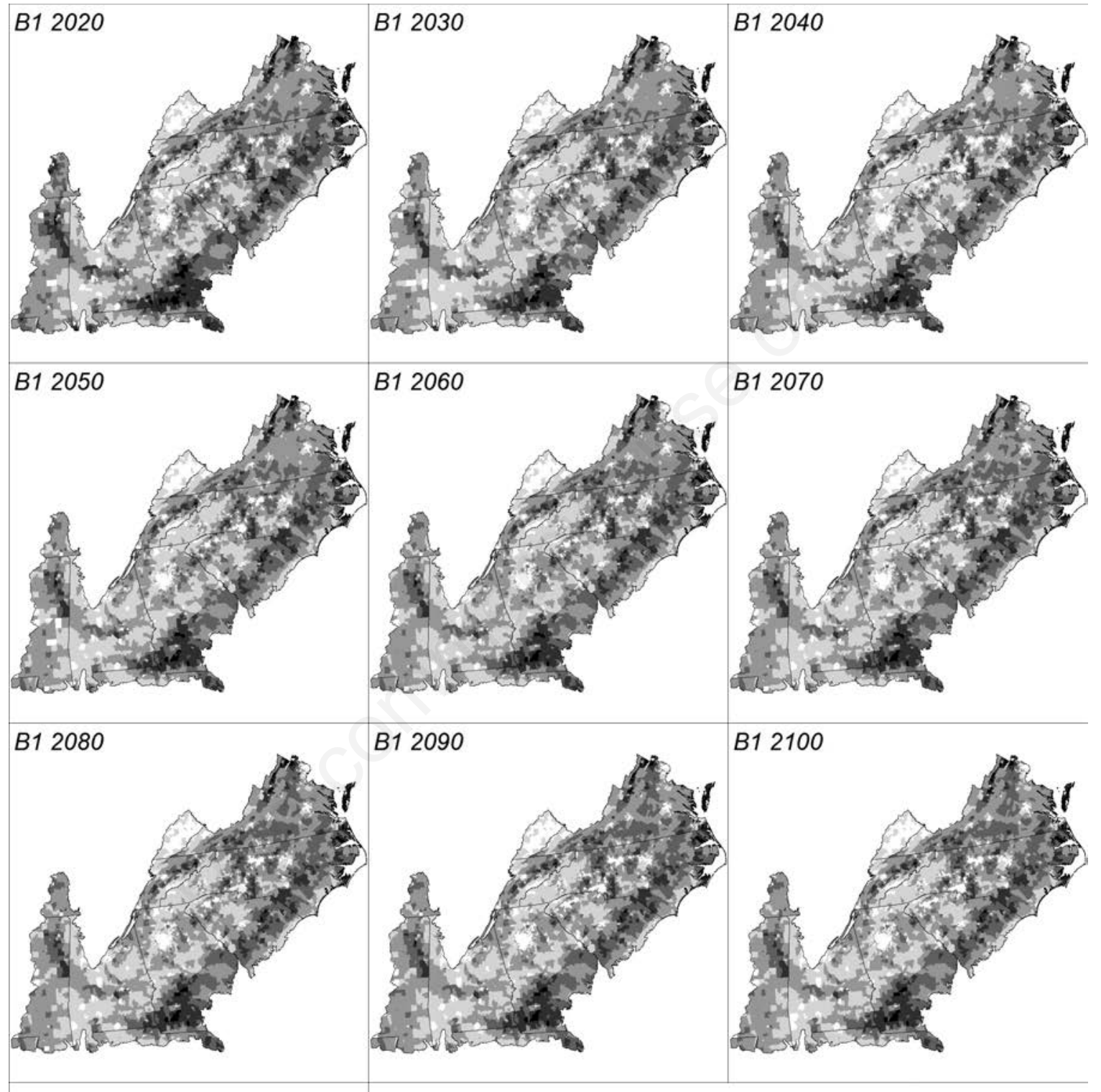

\section{Potential Land Cover Suitability}

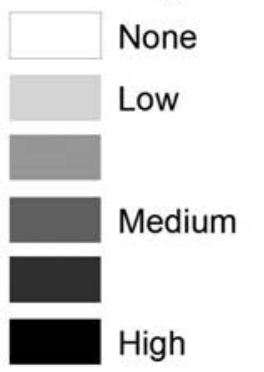

Figure 5. The B1 scenario is characterized by rapid changes in economic structures toward a service and information economy, with the introduction of clean, resource-efficient technologies. The scenario results in a decrease in potential land cover suitability that levels off around year 2040. 
projected land cover data to analyze fragmentation statistics per census tract. However, this altered the census tract's overall shape. After the conversion, the census tract polygons had a jagged, gridlike shape, rather than the census tract shapes defined by the United States Census Bureau. This was necessary to perform the analysis in FRAGSTATS 4.2. The projected land cover data and the census tract polygons were analyzed in FRAGSTATS 4.2 as GeoTIFF, requiring the data to be in raster format. There may be some error at a very fine resolution along census tract boundaries following this conversion, but again, the analysis is intended to be examined at a broad scale rather than at a very fine scale, making this limitation acceptable. Future researchers who expand upon

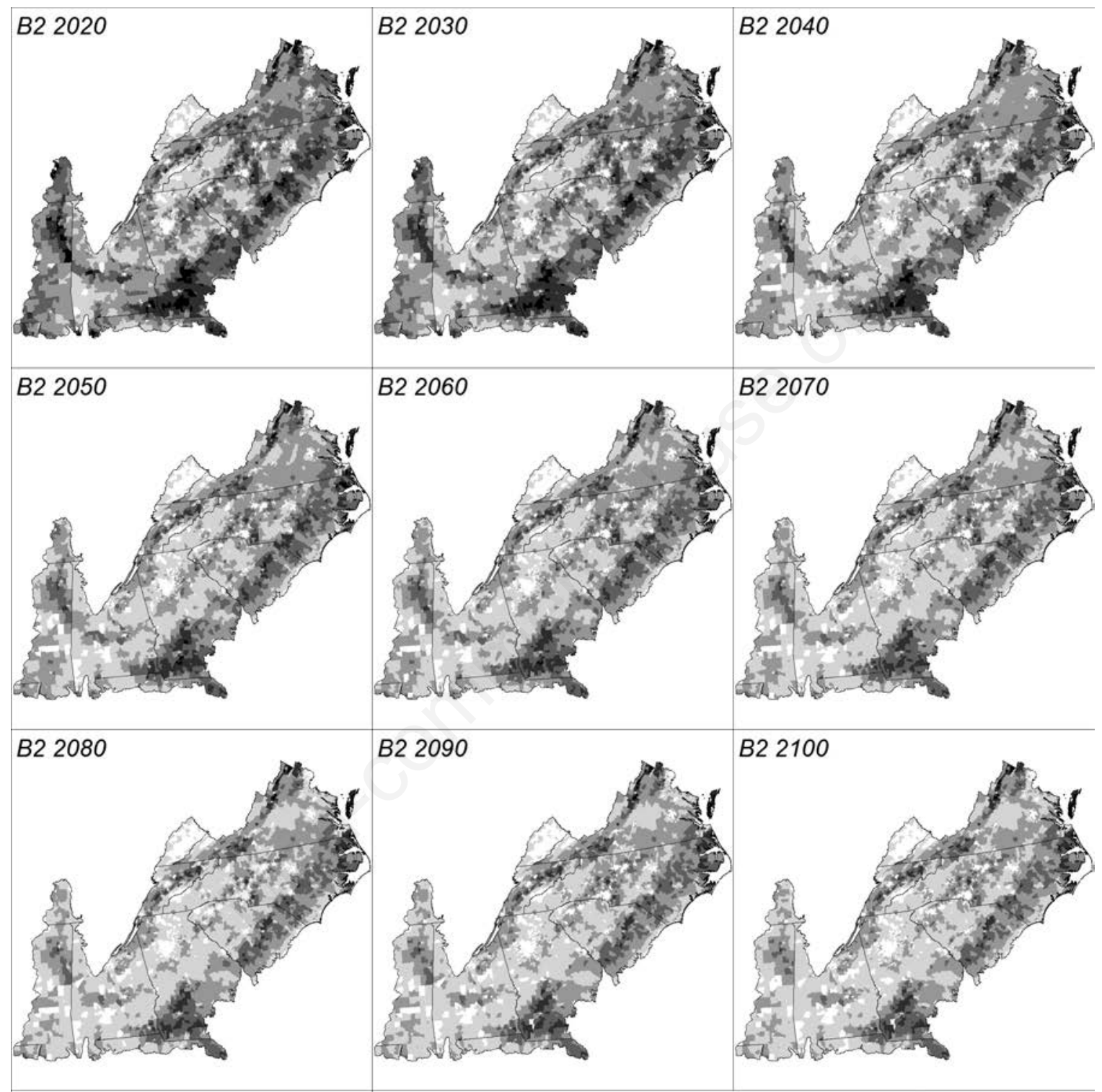

\section{Potential Land Cover Suitability}

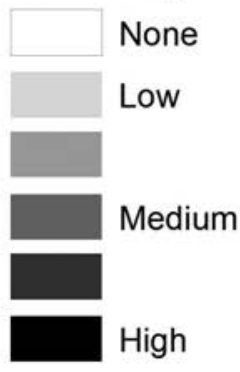

Figure 6. The B2 scenario represents an emphasis on local solutions to economic, social, and environmental sustainability needs. Global population gradually decreases over time with less rapid and more diverse technological change compared to the A1B and B1 scenarios. This scenario results in the largest decrease in potential land cover suitability, leveling off below the B1 scenario's results around year 2060. 
this study should consider the underlying structure of the four land cover types analyzed in this research. In addition, future research should examine land cover types in a narrower perspective, rather than arbitrarily aggregating land cover types to four broad categories. For example, future research related to this study could examine the impacts of deciduous, evergreen, and mixed forests on Lyme disease distribution. Furthermore, when finer resolution projected land cover data become available, larger scale studies should be explored at the state or even county level.

In contrast to the ecological variables considered in this study, future research should implement a diverse range of demographic variables when investigating future Lyme disease distribution, considering the importance of demographics on the dissemination of this disease. These demographics should include, but not be limited to, the demographic variables found to be significantly correlated with Lyme disease distribution by Seukep et al. (2015): population density, median age, and median household income.

While the current extent of Lyme disease includes the eastern U.S., the upper Midwest, and the west coast, 95\% of all Lyme disease cases in the U.S. are contracted along the East coast (CDC, 2017a). In addition, five counties that were not previously considered endemic have met the clinical surveillance criteria for Lyme disease in North Carolina, suggesting a continued southward advance (Lantos et al., 2015). No previous study has attempted to use land cover variables correlated with Lyme disease in its present endemic area to project areas where the Lyme disease transmission cycle may be supported under different scenarios. This study has identified areas in the south-eastern U.S. potentially at risk of Lyme disease if it expands into these areas, using projected land cover data developed under four scenarios representing a diverse set of assumptions for population, economic, and technological change (IPCC, 2018a).

\section{Conclusions}

The results of this research demonstrate that, based on the significant environmental variables found by Seukep et al. (2105), it is possible to reduce Lyme disease risk, as argued by Jackson et al. (2006a, 2006b). If we have high energy and resource demands, and delayed development of renewable energy, the conditions appear to support the Lyme disease transmission cycle (IPCC, 2018b). However, if we focus on developing renewable energies and promoting sustainable practices, then the Lyme disease transmission cycle could be reduced in the future based on the land cover variables associated with this risk. As humans modify the surrounding environment, the choices made can contribute to or prevent disease emergence.

As Lyme disease continues to emerge in the south-eastern U.S., these results can support city planners' efforts in these areas to consider impacts of landscape modification, potentially reducing Lyme disease transmission. The projected land cover scenarios represent four different future scenarios that signify the conditions that could lie ahead regarding emissions, population growth, economic growth, technological expansion, and environmental sustainability to name a few. Health officials can pinpoint areas of concern in which planners and developers can consider the amount of developed and herbaceous land, as well as levels of edge environments, when creating new development projects to limit ideal environments for host-reservoir interaction, and education and surveillance efforts can be targeted in high suitability areas.

\section{References}

Brownstein JS, Skelly DK, Holford TR, Fish D, 2005. Forest fragmentation predicts local scale heterogeneity of Lyme disease risk. Oecologia 146:469-75.

Centers for Disease Control and Prevention (CDC), 2017a. Data and Statistics, Lyme disease, CDC. Available from https:/www.cdc.gov/lyme/stats/index.html Accessed: January 25, 2018.

Centers for Disease Control and Prevention (CDC), 2017b. Lyme disease maps, Lyme Disease, CDC. Available from: https://www.cdc.gov/lyme/stats/maps.html Accessed: February 1, 2018.

ESRI, 2017. ArcGIS 10.5. Available from: http://desktop.arcgis. com/en/arcmap/

Horobik V, Keesing F, Ostfeld RS, 2007. Abundance and Borrelia burgdorferi-infection prevalence of nymphal Ixodes scapularis ticks along forest-field edges. EcoHealth 3:262-8.

Intergovernmental Panel on Climate Change (IPCC), 2018a. IPCC - Definitions and role of scenarios. Available from http://www.ipcc.ch/ipccreports/tar/wg2/index.php?idp=125 Accessed: April 16, 2018.

Intergovernmental Panel on Climate Change (IPCC), 2018b. IPCC emissions scenarios. Available from: http://www.ipcc.ch/ipccreports/sres/emission/index.php?idp=98 Accessed: April 5, 2018.

Intergovernmental Panel on Climate Change (IPCC), 2018c. IPCC Working Group I: the scientific basis. Available from: https://www.ipcc.ch/ipccreports/tar/wg1/029.htm\#storya1

Jackson LE, Hilborn ED, Thomas JC, 2006. Towards landscape design guidelines for reducing Lyme disease risk. Int J Epidemiol 35:315-22.

Jackson L, Levine J, Hilborn E, 2006. A comparison of analysis units for associating Lyme disease with forest-edge habitat. Commun Ecol 7:189-97.

Khatchikian CE, Prusinski M, Stone M, Backenson PB, Wang I-N, Levy MZ, Brisson D, 2012. Geographical and environmental factors driving the increase in the Lyme disease vector Ixodes scapularis. Ecosphere 3:85.

Lantos PM, Nigrovic LE, Auwaerter PG, Fowler VG, Ruffin F, Brinkerhoff RJ, Reber J, Williams C, Broyhill J, Pan WK, Gaines DN, 2015. Geographic expansion of Lyme disease in the Southeastern United States, 2000-2014. Open Forum Infect Dis 2:1-8.

Li J, Kolivras KN, Hong Y, Duan Y, Seukep SE, Prisley SP, Campbell JB, Gaines DN, 2014. Spatial and temporal emergence pattern of Lyme disease in Virginia. Am J Trop Med Hyg 91:1166-72.

Lindgren E, Jaenson TGT, 2006. Lyme borreliosis in Europe: influences of climate and climate change, epidemiology, ecology and adaptation measures. World Health Organization, Geneva, Switzerland. Available from: http:/www.euro. who.int/en/publications/abstracts/lyme-borreliosis-in-europe.influences-of-climate-and-climate-change,-epidemiology,ecology-and-adaptation-measures

McGarigal K, Cushman S, Ene E, 2012. FRAGSTATS v4: Spatial pattern analysis program for categorical and continuous maps. University of Massachusetts, Amherst, USA. Available from: http://www.umass.edu/landeco/research/fragstats/fragstats.ht $\mathrm{ml}$

Mysterud A, Easterday WR, Stigum VM, Aas AB, Meisingset EL, 
Viljugrein H, 2016. Contrasting emergence of Lyme disease across ecosystems. Nature Commun 7:11882.

Ogden NH, Maarouf A, Barker IK, Bigras-Poulin M, Lindsay LR, Morshed MG, O'callaghan CJ, Ramay F, Waltner-Toewns D, Charron DF, 2006. Climate change and the potential for range expansion of the Lyme disease vector Ixodes scapularis in Canada. Int J Parasitol 36:63-70.

Seukep SE, Kolivras KN, Hong Y, Li J, Prisley SP, Campbell JB, Gaines DN, Dymond RL, 2015. An examination of the demographic and environmental variables correlated with Lyme disease emergence in Virginia. EcoHealth 12:634-44.

Simon JA, Marrotte RR, Desrosiers N, Fiset J, Gaitan J, Gonzalez A, Koffi JK, Lapointe FJ, Leighton PA, Lindsay LR, Logan T, Milord F, Ogden NH, Rogic A, Roy-Dufresne E, Suter D, Tessier N, Millien V, 2014. Climate change and habitat fragmentation drive the occurrence of Borrelia burgdorferi, the agent of Lyme disease, at the northeastern limit of its distribution. Evol Appl 7:750-64.
Sleeter BM, Sohl TL, Bouchard MA, Reker RR, Soulard CE, Acevedo W, Griffith GE, Sleeter RR, Auch RF, Sayler KL, Prisley S, Zhu Z, 2012. Scenarios of land use and land cover change in the conterminous United States: utilizing the special report on emission scenarios at ecoregional scales. Global Environ Change 22:896-914.

Sohl TL, Sleeter BM, Zhu Z, Sayler KL, Bennett S, Bouchard M, Reker R, Hawbaker T, Wein A, Liu S, Kanengieter R, Acevedo W, 2012. A land-use and land-cover modeling strategy to support a national assessment of carbon stocks and fluxes. Appl Geogr 34:111-24.

Tran PM, Waller L, 2013. Effects of landscape fragmentation and climate on Lyme disease incidence in the Northeastern United States. EcoHealth 10:394-404.

U.S. Geological Survey (USGS), 2012. Carbon conterminous United States land-use/Land-Cover Mosaics 1992-2100. Sioux Falls, SD. Available from: https://landcover-modeling.cr. usgs.gov/ 